RESEARCH ARTICLE

\title{
Evaluation of COVID-19 Patients with Chronic Kidney Disease
}

\author{
Yasaman Sadat Keshmiri', Sina Khosravi Mirzaie ${ }^{1}$, Shahnaz Sali², Davood Yadegarynia², Sara \\ Abolghasemi ${ }^{2}$, Shabnam Tehrani ${ }^{2}$, Amir Zamani ${ }^{1}$, Mohamad Mehdi Derisi ${ }^{1}$
}

\begin{abstract}
${ }^{1}$ School of Medicine, Shahid Beheshti University of Medical Sciences, Tehran, Iran
2Infectious Diseases and Tropical Medicine Research Center, Shahid Beheshti University of Medical Sciences, Tehran, Iran
\end{abstract}

\begin{abstract}
Objectives: The present study seeks to provide insight into managing patients with chronic kidney disease (CKD) infected with COVID-19.
\end{abstract}

Methods: Patients with COVID-19 with CKD were included in the study. The eligible patients were divided into four groups: 1) patients who were not on dialysis, 2) patients on maintenance dialysis, 3) patients who underwent dialysis following COVID-19, 4) patients with a history of a kidney transplant. After reviewing clinical charts, nursing records, laboratory findings, radiological reports, and other medical records of CKD patients with COVID-19 confirmed infection, clinical presentation, laboratory data, radiology findings, and results were extracted from documented medical records. The epidemiological, clinical, laboratory and outcome characteristics of the subgroups were evaluated and compared.

Results: Seventy-eight patients were included into the study. Hypertension (50 cases, $72.5 \%$ ), diabetes (44 cases, 63.8\%), and Cardiovascular disease (26 cases, 38.2\%) were the most common risk factors in the studied patients. Among all participants, 40 (52.6\%) patients died. The most common symptom was dyspnea (56.6\%), followed by dry cough (38.7\%). Comparison of blood, inflammatory, biochemical, and clinical indices among the patients' groups show that LDH $(P=0.022), A S T(P=0.038)$, and ALT $(P=0.004)$ indices were significantly different between groups of patients. According to the results in Table 3, Unilateral ground-glass opacity (GGO) in the radiological findings of the Nondialysis CKD group was significantly $(P=0.50)$ higher than the other groups.

Conclusion: It can be concluded that CKD is one of the critical factors that can cause poor prognosis in COVID-19 patients. J Microbiol Infect Dis 2021; 11(3):152-158.

Keywords: COVID19, chronic kidney disease, Dialysis, Transplant

\section{INTRODUCTION}

Today's world is facing a massive wave of COVID-19 virus disease. Thirty years after the virus was first discovered in the 1930s, evidence of its pathogenicity has been established in humans [1]. In December 2019, a viral outbreak of the same family was reported from Wuhan, China [2,3], and the spread of the disease has since infected more than 14 million people and killed more than 600,000 worldwide [4].
The presence of underlying diseases such as diabetes, hypertension, cardiovascular disorders, and COPD can affect the severity of the disease in different people and the mortality rate [5-7]. For example, chronic kidney disease (CKD) is a common disease that can lead to impaired renal function by reducing the glomerular filtration rate (GFR] [8]. Statistics show that in 2017, over 5 million patients worldwide were suffering from the disease [9]. Old age and the presence of underlying diseases in most patients with this 
disease are among the factors that make CKD patients more susceptible to COVID-19.

In CKD, the glomerular filtration rate decreases due to a decrease in the number of nephrons. Adaptive responses are then generated by factors such as vasoactive hormones, growth factors, and cytokines [8]. The presence of cytokines causes a cytokine storm, activating the angiotensin II pathway, leading to increased blood coagulation and microangiopathy [10]. Studies have shown that ICU hospitalization rates and mortality in CKD patients are significantly higher due to symptoms such as cough, severe shortness of breath, and extreme fatigue [11,12]. Also, the results of laboratory tests of these patients have shown that ferritin and CRP in CKD patients are associated with a significant increase, which can be related to their severe inflammatory status [13].

Despite a large number of CKD patients, research in this area has been relatively largely neglected. In this study, we describe 78 patients in the Labafinejad Hospital in Tehran, Iran. Clinical manifestations, radiological findings, laboratory data, and results are reviewed to provide insights for physicians in managing patients with chronic kidney disease infected with COVID-19.

\section{METHODS}

\section{Study design}

This study, designed as a cross-sectional study from March 2, 2020, to May 9, 2020, has been approved by the Ethics Committee in Biomedical Research of Shahid Beheshti University of Medical Sciences with the code (IR.SBMU.REC.1399.018). Patients with the novel coronavirus (COVID-19) referred to Labbafinezhad Hospital in Tehran were included in the study if they met the inclusion criteria (cough, fever, fatigue, myalgia, chest pain, dyspnea, other upper respiratory symptoms, and gastrointestinal symptoms). Diagnosis of COVID-19 patients was based on the WHO interim guidance, a confirmed COVID-19 patient defined as an individual with a positive reverse transcriptase-polymerase chain reaction (RT-PCR) result or a patient with common COVID-19 symptoms and a computed tomography scan (CT-scan) compatible with COVID-19 pattern confirmed by experts [14]. In addition, the written informed consent form was obtained from all patients by the Ethics Commission of the hospital.

A total of 91 patients presented within the specified period, and 78 patients were eligible for the study. Patients were divided into four subgroups (Figure 1): 1) patients who were not on dialysis, 2) patients on maintenance dialysis, 3) patients who underwent dialysis following COVID-19, 4) patients with a history of a kidney transplant.

After reviewing clinical charts, nursing records, laboratory findings, radiological reports, and other medical records of CKD patients with COVID-19 confirmed infection, clinical presentation, laboratory data, radiology findings, and results were extracted from documented medical records using data collection forms. Laboratory tests were performed again before discharge. The quick COVID-19 Severity Index (qCSI) was used to assess the severity of COVID-19 in patients. The qCSI ultimately requires only three variables, all of which are accessible at the bedside [26].

\section{Statistical Analysis}

The collected data were summarized as descriptive profiles using mean, median, standard deviation, and variance. Patients' percentages, mean, median, and standard deviation were calculated within different groups for specific variables. Independent ttest, paired t-test, and chi-square were used to compare the clinical features of patients with COVID-19. A $p$-value of less than 0.05 was considered to indicate statistical significance. All the statistical analyses were performed by the SPSS v.26.0 (Chicago, Illinois, USA).

\section{RESULTS}

Based on Table 1, of the 78 patients studied, $53(68.8 \%)$ were female. The average age of patients was 64.04 years (32-96). Among the included patients, $23(29.48 \%)$ were not on dialysis, $28(35.89 \%)$ were on maintenance dialysis, seven $(8.97 \%)$ underwent dialysis following COVID-19, and $20(8.97 \%)$ patients had a history of kidney transplantation. Hypertension (50 cases, $72.5 \%$ ), diabetes (44 cases, $63.8 \%$ ), and Cardiovascular disease (26 cases, $38.2 \%$ ) were the most common risk factors in the studied patients. Among all participants, $40(52.6 \%)$ patients died. The most common symptom was dyspnea $(56.6 \%)$, followed by dry cough (38.7\%). 


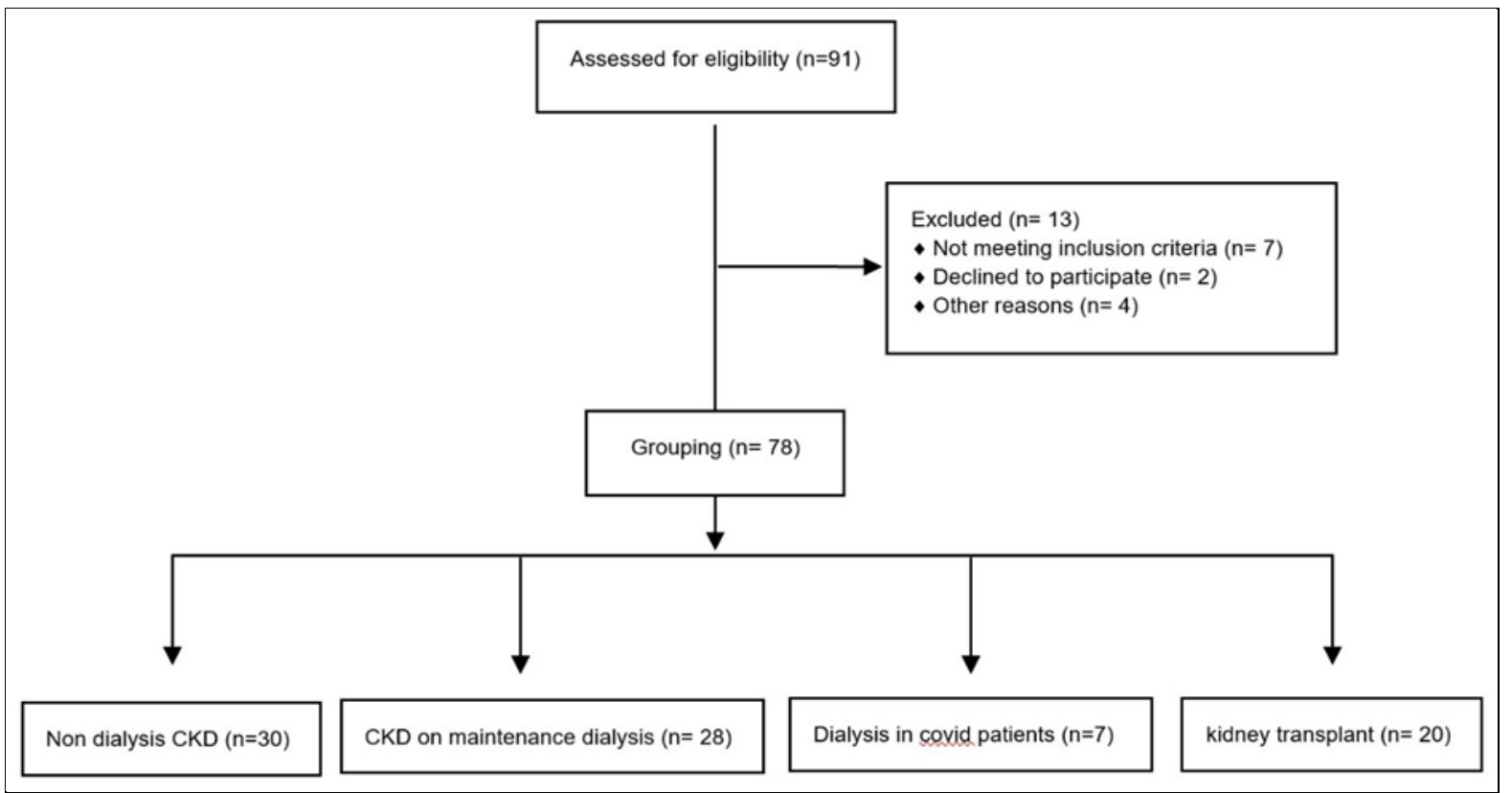

Figure 1. The CONSORT diagram.

Table 1. Clinical and demographic features of patients based on renal therapy using ANOVA statistical method.

\begin{tabular}{|c|c|c|c|c|c|c|}
\hline Variables & Total & $\begin{array}{l}\text { Non-dialysis } \\
\text { CKD }(n=23)\end{array}$ & $\begin{array}{c}\text { CKD on } \\
\text { maintenance } \\
\text { dialysis }(n=28)\end{array}$ & $\begin{array}{c}\text { Dialysis in } \\
\text { Covid-19 } \\
\text { patients }(n=7)\end{array}$ & $\begin{array}{c}\mathrm{KT} \\
(\mathrm{n}=20)\end{array}$ & $\begin{array}{c}\mathrm{p}- \\
\text { value }\end{array}$ \\
\hline Age (mean $\pm S D)$ & $\begin{array}{c}64.4 \pm \\
15.0\end{array}$ & $65.9 \pm 12.4$ & $68.3 \pm 14.82$ & $62.00 \pm 22.62$ & $\begin{array}{l}57.00 \pm \\
13.29\end{array}$ & 0.069 \\
\hline $\operatorname{Sex}(M), n(\%)$ & $24(31.2)$ & $6(26.1)$ & $5(18.5)$ & $3(42.5)$ & $10(50)$ & \multirow{2}{*}{0.111} \\
\hline Female, n (\%) & $53(68.8)$ & $17(73.9)$ & $22(81.5)$ & $4(57.1)$ & $10(50)$ & \\
\hline \multicolumn{7}{|l|}{$\begin{array}{l}\text { Initial symptoms, } \\
\mathrm{n}(\%)\end{array}$} \\
\hline Fever & $22(30.1)$ & $8(34.8)$ & $9(37.5)$ & $1(14.3)$ & $4(21.1)$ & 0.529 \\
\hline Chills & $10(13.2)$ & $2(8.7)$ & $2(7.4)$ & $1(14.3)$ & $25(26.3)$ & 0.270 \\
\hline Dry cough & $29(38.7)$ & $9(39.1)$ & $11(42.3)$ & $3(42.9)$ & $30(31.6)$ & 0.882 \\
\hline Dyspnea & $43(56.6)$ & $15(65.2)$ & $15(55.6)$ & $3(42.9)$ & $10(52.6)$ & 0.701 \\
\hline Gl symptoms & $19(25)$ & $6(26.1)$ & $7(25.0)$ & $2(28.6)$ & $4(20)$ & 1.000 \\
\hline \multicolumn{7}{|l|}{$\begin{array}{l}\text { Comorbidities, } \\
\text { n (\%) }\end{array}$} \\
\hline Diabetes & $44(63.8)$ & $15(75)$ & $15(60.0)$ & $3(50.0)$ & $11(61.1)$ & 0.407 \\
\hline Hypertension & $50(72.5)$ & $14(70.0)$ & $19(76.0)$ & $4(66.7)$ & $13(65)$ & 0.743 \\
\hline CVD & $26(38.2)$ & $8(40.0)$ & $11(44.0)$ & $0(0.0)$ & $7(41.2)$ & 0.178 \\
\hline \multicolumn{7}{|c|}{$\begin{array}{l}\text { Quick COVID severity } \\
\text { Index*, n (\%) }\end{array}$} \\
\hline Low-risk group & 0 & 0 & 0 & 0 & 0 & \multirow{4}{*}{0.482} \\
\hline $\begin{array}{l}\text { Low-intermediate } \\
\text { risk group }\end{array}$ & $20(35.7)$ & $5(29.4)$ & 7 (33.3) & $3(75.0)$ & $5(31.3)$ & \\
\hline $\begin{array}{l}\text { High-intermediat } \\
\text { group }\end{array}$ & $14(25)$ & $2(11.8)$ & 7 (33.3) & $0(0.0)$ & $5(31.3)$ & \\
\hline High-risk group & $22(28.2)$ & $10(58.8)$ & $7(33.3)$ & $1(25.0)$ & $6(37.5)$ & \\
\hline Death, n (\%) & $40(52.6)$ & $18(78.3)$ & $20(71.4)$ & $0(0)$ & $2(10.5)$ & $<0.001$ \\
\hline ICU care, n (\%) & $34(44.7)$ & $14(60.86)$ & $16(57.14)$ & $2(33.3)$ & $2(10.52)$ & $<0.001$ \\
\hline
\end{tabular}


Table 2. Laboratory data in admission and discharge of COVID-19 patients using ANOVA statistical method.

\begin{tabular}{|c|c|c|c|c|c|}
\hline Variable & $\begin{array}{c}\text { Non-dialysis CKD } \\
(n=23)\end{array}$ & $\begin{array}{c}\text { CKD on maintenance } \\
\text { dialysis }(n=28)\end{array}$ & $\begin{array}{l}\text { Dialysis in Covid-19 } \\
\text { patients }(n=7)\end{array}$ & $\mathrm{KT}(\mathrm{n}=20)$ & $\begin{array}{c}\mathrm{p}- \\
\text { value }\end{array}$ \\
\hline \multicolumn{6}{|l|}{$\begin{array}{l}\text { CBC at Ad- } \\
(\text { IQR) }\end{array}$} \\
\hline RBC & $3.8(3.0-4.7)$ & $4.13(3.3-4.57)$ & $3.9(3.42-4.42)$ & $3.8(3.10-3.27)$ & 0.572 \\
\hline Hct & $33.20(27.5-38.5)$ & $36.05(33.22-39.75)$ & $33.10(30.10-35.32)$ & 35.65 (28.95-38.07) & 0.229 \\
\hline $\mathrm{Hb}:$ & $9.40(8.50-12.50)$ & $11.15(9.65-12.87)$ & $10.15(9.25-10.75)$ & $10.85(8.92-12.65)$ & 0.301 \\
\hline PLT & $205.0(127.0-253.0)$ & $192.0(116.0-289.0)$ & $289(217.0-411.5)$ & $159.0(124-221)$ & 0.129 \\
\hline WBC & $9.50(6.90-12.90)$ & $8.45(6.55-11.95)$ & $7.45(6.20-9.62)$ & $7.85(4.85-10.10)$ & 0.503 \\
\hline Neutrophil & $80.0(72.75-92-75)$ & $85.0(79.0-87.0)$ & $77.0(75.0-82.0)$ & $80.0(75.75-89.0)$ & 0.546 \\
\hline Lymphocytes & $14.5(5.0-22.25)$ & $14.0(10.0-17.0)$ & $18.0(13.0-19.50)$ & $16.0(7.50-20.0)$ & 0.664 \\
\hline \multicolumn{6}{|l|}{$\begin{array}{l}\text { Infection- } \\
\text { related } \\
\text { indices }\end{array}$} \\
\hline ESR & $50.0(16.50-83.50)$ & $30.50(20.25-72.25)$ & $64.50(51.0-78.0)$ & $30.0(26.0-57.0)$ & 0.773 \\
\hline CRP & $43.10(33.0-55.25)$ & $38.0(21.0-47.0)$ & $42.5(5.87-60.0)$ & $38.0(14.25-53.42)$ & 0.409 \\
\hline \multicolumn{6}{|l|}{ Biochemical } \\
\hline Albumin & $3.0(2.75-3.4)$ & $2.8(2.5-3.35)$ & $3.4(3.15-3.57)$ & $3.2(3-3.9)$ & 0.116 \\
\hline Troponin & $0.023(0.005-0.80)$ & $0.37(0.007-0.258)$ & $0.023(0.001-0.428)$ & $0.025(0.012-0.75)$ & 0.674 \\
\hline LDH & 591 (433.0-1354.0) & $625(490-877)$ & $329(266.0-483.0)$ & $447.5(353.3-584.5)$ & $0.022^{*}$ \\
\hline CPK & $124(67-451)$ & $118.5(44-352.25)$ & $42(41.5-134.5)$ & $166(70-351.5)$ & 0.241 \\
\hline Urea & $124.5(56-212.5)$ & $108.5(63-176)$ & $95(50-119)$ & $101(83.25-149)$ & 0.592 \\
\hline $\mathrm{Cr}$ & $3.79(2.39-8.10)$ & $2.79(1.93-5.45)$ & $3.07(1.98-5.31)$ & $3.9(2.79-6.48)$ & 0.64 \\
\hline AST & $40.5(21.25-71.5)$ & $28(17-74)$ & $13(12-19)$ & $26.5(18.75-39.25)$ & $0.038^{*}$ \\
\hline ALT & $32(19-74.5)$ & $21(11-75)$ & $8(3.25-9)$ & $15.5(11.5-35)$ & $0.004^{*}$ \\
\hline Bil total & $0.8(0.55-1.65)$ & $0.75(0.47-1.1)$ & $0.8(0.5-1.1)$ & $0.7(0.5-2.3)$ & 0.903 \\
\hline Bil direct & $0.2(0.2-0.4)$ & $0.2(0.2-3.25)$ & $0.15(0.1-0.2)$ & $0.2(0.15-1)$ & 0.515 \\
\hline \multicolumn{6}{|l|}{ Vital signs } \\
\hline Temperature & $37(36.5-37.5)$ & $37(36.8-37)$ & $36.5(36.15-36.67)$ & $37.1(36.65-37.45)$ & 0.033 \\
\hline $\mathrm{RR}$ & $19(17-26)$ & $18(16.5-24)$ & $18(17.25-22.5)$ & $18(17.25-21)$ & 0.731 \\
\hline PR & $85(80-92)$ & $82(80-93.5)$ & $82(70-90)$ & $86(86-99.9)$ & 0.859 \\
\hline $\begin{array}{l}\text { Systolic BP } \\
\text { (Mean } \pm \text { SD) }\end{array}$ & $121.95 \pm 26.36$ & $126.2 \pm 34.48$ & $133.66 \pm 20.94$ & $123.73 \pm 27.82$ & 0.272 \\
\hline $\begin{array}{l}\text { Diastolic BP } \\
\text { (Mean } \pm S D)\end{array}$ & & & & & \\
\hline O2 Sat & $\begin{array}{c}72.57 \pm 16.16 \\
87.5(85.25-94.25)\end{array}$ & $\begin{array}{c}74.39 \pm 15.47 \\
90(82-94.5)\end{array}$ & $\begin{array}{l}76.33 \pm 10.32 \\
95(93.75-97)\end{array}$ & $\begin{array}{c}78.15 \pm 17.98 \\
90(84.25-93.75)\end{array}$ & $\begin{array}{l}0.427 \\
0.073\end{array}$ \\
\hline
\end{tabular}

Ad: Admission; RBC: Red Blood Cell Htc: Hematocrit, WBC: White Blood Cell PLT: Platelet Dis: Discharge; Bil :Bilirubin, Trop=troponin; LDH:lactate dehydrogenase; Cr:creatinine; ICU:intensive care unit.

Table 3. Radiologic findings and vital signs using ANOVA statistical method.

\begin{tabular}{|c|c|c|c|c|c|}
\hline Variables & $\begin{array}{l}\text { Non-dialysis } \\
\text { CKD }(n=23)\end{array}$ & $\begin{array}{l}\text { CKD on maintenance } \\
\text { dialysis }(n=28)\end{array}$ & $\begin{array}{l}\text { Dialysis in COVID- } \\
19 \text { patients }(n=7)\end{array}$ & $\mathrm{KT}(\mathrm{n}=20)$ & $\begin{array}{c}\mathrm{p}- \\
\text { value }\end{array}$ \\
\hline \multicolumn{6}{|l|}{$\begin{array}{l}\text { Radiologic findings, } n \\
(\%)\end{array}$} \\
\hline Unilateral GGO & $6(54.5)$ & $3(20)$ & $1(20.0)$ & $1(7.1)$ & $0.050^{*}$ \\
\hline Bilateral GGO & $5(45.5)$ & $5(33.3)$ & $3(60.0)$ & $9(64.3)$ & 0.383 \\
\hline Pleural effusion & $5(45.5)$ & $5(33.3)$ & $4(80.0)$ & $5(35.7)$ & 0.337 \\
\hline Collapse & $1(9.1)$ & $0(0.0)$ & $0(0.0)$ & $1(7.1)$ & 0.621 \\
\hline Consolidation & $0(0)$ & $1(6.7)$ & $0(0.0)$ & $1(7.1)$ & 1.000 \\
\hline Emboli & $0(0)$ & $1(6.7)$ & $0(0.0)$ & $0(0.0)$ & 1.000 \\
\hline Band & $1(9.1)$ & $5(33.3)$ & $0(0.0)$ & $3(21.4)$ & 0.378 \\
\hline \multicolumn{6}{|l|}{ Drugs, n (\%) } \\
\hline Hydroxyqloroquine & $20(87)$ & $20(76.9)$ & $7(100.0)$ & $19(95.0)$ & 0.283 \\
\hline Kaletra & $12(52.2)$ & $17(65.4)$ & $3(42.9)$ & $5(25.0)$ & 0.054 \\
\hline INF & $2(8.7)$ & $0(0.0)$ & $0(0.0)$ & $0(0.0)$ & 0.332 \\
\hline Anibiotics & $22(95.7)$ & $26(100.0)$ & $7(100.0)$ & $20(100.0)$ & 0.658 \\
\hline
\end{tabular}

GGO=ground glass opacity, GCS=Glasgow coma scale 
Comparison of blood, inflammatory, biochemical, and clinical indices between the four groups in patients show that LDH $(p=0.022)$, AST $(p=0.038)$, and ALT $(p=0.004)$ indices were significantly different between groups of patients. Unilateral ground-glass opacity (GGO) in the radiological findings of the non-dialysis CKD group was significantly higher $(P=0.50)$ than the other groups (Table $3)$. However, other radiological indices did not differ significantly between different groups. On the other hand, no significant difference was observed in the type of drug used by the groups.

\section{DISCUSSION}

COVID-19 can cause a variety of symptoms in patients. Furthermore, these clinical symptoms have different severity and nature depending on the history of underlying diseases, physiology, and severity of infection in each patient. The results indicate that in this study, the most common symptom in all patients was dyspnea. Also, dyspnea was the most common symptom in all patients on dialysis who were on maintenance dialysis or underwent dialysis following COVID-19. A previous study including five patients on hemodialysis with COVID-19 revealed that diarrhea and non-respiratory symptoms were the most common symptoms [15]. Another case report similarly reported that nausea and vomiting were the first symptoms of dialysis COVID-19 patients [16]; however, the prevalence of gastrointestinal symptoms was only $25 \%$ in this study. Also, in patients with a history of a kidney transplant, $52.6 \%$ had dyspnea, while the study of Akaline et al. declares that the initial symptom in these patients was fever [17]. However, given the nature and target tissue of the COVID-19 infectious agent, the prevalence of respiratory disorders can be predictable.

Contrary to the previous COVID-19 studies, in this study, there were more women $(68.8 \%)$ than men (31.2\%) [18-21]. However, looking at the mortality rate of patients, it can be seen that the number of deaths in women $(52.8 \%)$ in the study was more than men $(44 \%)$ which according to the changes in sex hormone levels among female patients with end-stage renal disease, these differences can be justified [22].
Based on the present study, $89.7 \%$ of patients had a history of underlying diseases. Furthermore, most patients with severe conditions had diabetes, hypertension, and coronary diseases, which is aligned with the data that have been reported $[21,23]$ so that, Comorbidities in patients with kidney disease are risk factors for poor outcomes in COVID19 [5]. Quick COVID-19 severity index (qCSI) results show $35.7 \%$ of patients were in the low intermediate group, meaning they have had a $30 \%$ chance of critical illness.

On the other hand, $28.2 \%$ of patients were in the high intermediate category, which means they have had a $44 \%$ risk of critical illness. This study declares that, even with the higher O2 saturation (mean=91.2) and normal respiratory rate (mean=16.71) in patients who underwent dialysis following COVID-19, the mortality rate was $80 \%$. While in patients without dialysis who had the lowest $\mathrm{O} 2$ saturation (mean $=86.73 \%$ ) and the highest respiratory rate (mean=22.86), the mortality rate was only $45.5 \%$.

In terms of laboratory data, the average level of creatinine in all patients was $4.37 \mathrm{mg} / \mathrm{dl}$, and between subgroups, patients on maintenance dialysis had the highest average creatinine level $(5.74 \mathrm{mg} / \mathrm{dl})$, contrary to the study of Ajaimy et al., which the median of creatinine in COVID-19 patients with kidney disease was $2 \mathrm{mg} / \mathrm{dl}$ [23]. Therefore, it cannot be said that there is a strong correlation between albumin levels and patient outcomes [24]. Furthermore, in our study, the mean LDH level in all patients was $667.058 \mathrm{U} / \mathrm{L}$, while in previous studies, the mean LDH level in COVID-19 patients without kidney disease was $261 \mathrm{U} / \mathrm{L}$ and in patients with CKD was $264 \mathrm{U} / \mathrm{L}[13,21]$. On the other hand, in our study, the mean level of LDH in patients with a history of kidney transplantation at the time of admission was $815 \mathrm{U} / \mathrm{L}$ and at the time of discharge was $119.66 \mathrm{U} / \mathrm{L}$, which is much higher than the amount reported in the same study (mean $\mathrm{LDH}$ level=336 U/L) [17]. Also, in line with other studies, the LDH level was higher in patients who died, and patients admitted to ICU, which shows the correlation between the high level of LDH and poor outcomes of patients [25].

Considering the patients' CT-Scan, aligning with other studies, bilateral ground-glass 
opacity was the most radiological finding $[21,23]$.

The implementation of the present study was accompanied by limitations that, for example, the evaluation of serum antibodies for COVID19 (IgG and IgM) and hematologic tests have not been conducted to determine viremia have not been carried out, which might have some helpful information regarding patients' outcomes. Finally, our explanation may be restricted because of the small sample size.

\section{Conclusion}

According to the results, dyspnea was the most common symptom in patients in this study, while the levels of LDH, AST, and ALT had the most changes. Also, the most common finding on a shelf CT scan is a bilateral dimming of the ground glass. Also, the most common finding on chest CT-Scan is bilateral ground-glass opacity. On the other hand, due to the number of deaths and ICU admissions, it can be concluded that CKD is one of the essential factors that can cause poor prognosis in COVID-19 patients. For this reason, it can be said that it is crucial to evaluate clinical manifestations, radiologic findings, laboratory data, and outcomes of COVID-19 patients with CKD to establish a perspective for physicians to manage patients.

\section{ACKNOWLEDGMENTS}

The authors appreciate all the doctors, nurses, and health care workers' efforts involved in the diagnosis and management of our patients. We acknowledge the Medical Record Department of Labbafinezhad Hospital for coordinating data collection for CKD patients with COVID-19 infection. We thank Keivan Ranjbar and Dr. Reza Shahriarirad for revising the manuscript. We would also like to thank all patients involved in this study.

The article has been published in Research Square as PREPRINT. For sure it is not the certain edition and this do not has any contradiction with Copyright and Publisher's policy.

Declaration of Conflicting Interests: The authors declare that they have no conflict of interest.

Author contribution: YSK and SKM contributed to the acquisition of data, drafting the article, and interpretation of data. SS contributed to the conception and design, and interpretation of data. ST and DY contributed to the initiation of the research and interpretation of data. $A Z$ and MMD Contributed to the analysis and interpretation of data. S.A. contributed to drafting the article and revising it critically for important intellectual content. All authors have read and approved the final version of the manuscript.

Availability of data and materials: Data supporting the results reported in the article can be found by academic researchers by sending an email to the corresponding author at dr.shsali@gmail.com

Ethics approval and consent to participate: This research has been approved by the Ethics Committee of Shahid Beheshti University of Medical Sciences with the approval code IR.SBMU.REC.1399.018. Written informed consent was obtained from all participants or their proxies.

Consent for publication: All participants or their proxies gave written consent for their personal or clinical details along with any identifying images to be published in this study.

Funding: Not applicable.

\section{REFERENCES}

1. Estola T. Coronaviruses, a new group of animal RNA viruses. Avian diseases. 1970; 14(2):330-6.

2. Hui DS, Azhar El, Madani TA, et al. The continuing 2019-nCoV epidemic threat of novel coronaviruses to global health - The latest 2019 novel coronavirus outbreak in Wuhan, China. Int J Infect Dis. 2020; 91:264-266.

3. Paules $\mathrm{Cl}$, Marston HD, Fauci AS. Coronavirus Infections-More Than Just the Common Cold. JAMA 2020; 323(8):707-8.

4. World Health Organization. WHO Coronavirus Disease (COVID-19) Dashboard. 2020. https://covid19.who.int/. Accessed July 202020.

5. Guan WJ, Liang $\mathrm{WH}$, Zhao $\mathrm{Y}$, et al. Comorbidity and its impact on 1590 patients with COVID-19 in China: a nationwide analysis. Eur Respir J 2020;55(5).

6. Wang B, Li R, Lu Z, Huang Y. Does comorbidity increase the risk of patients with 
COVID-19: evidence from meta-analysis. Aging 2020;12(7):6049-57.

7. Sanyaolu A, Okorie C, Marinkovic A, et al. Comorbidity and its Impact on Patients with COVID-19. SN Comprehensive Clin Med 2020:1-8

8. Bargman JM, Skorecki KL. Chronic Kidney Disease. In: Jameson JL, Kasper DL, Longo DL, Fauci AS, Hauser SL, Loscalzo J, Editors. Harrison's Principles of Internal Medicine; 2018; p: 2111-2121

9. Bikbov B, Purcell CA, Levey AS, et al. Global, regional, and national burden of chronic kidney disease, 1990-2017: a systematic analysis for the Global Burden of Disease Study 2017. Lancet 2020; 395 (10225):709-733.

10. Batlle D, Soler MJ, Sparks MA, et al. Acute Kidney Injury in COVID-19: Emerging Evidence of a Distinct Pathophysiology. J Am Soc Nephrol 2020; 31(7):1380-1383.

11. Henry BM, Lippi G. Chronic kidney disease is associated with severe coronavirus disease 2019 (COVID-19) infection. Intern Urolog Nephrol 2020; 52(6):1193-1194.

12. Cheng $Y$, Luo $R$, Wang $K$, et al. Kidney disease is associated with in-hospital death of patients with COVID-19. Kidney Int 2020; 97(5):829-838.

13. Jung $H Y$, Lim JH, Kang $S H$, et al. Outcomes of COVID-19 among Patients on InCenter Hemodialysis: An Experience from the Epicenter in South Korea. J Clin Med 2020; 9(6): 1688. doi: 10.3390/jcm9061688.

14. World Health O. Clinical management of COVID-19: Interim Guidance, May 272020. Geneva: World Health Organization. 2020. https://apps.who.int/iris/handle/10665/332196. Accessed July 202020.

15. Wang $\mathrm{R}$, Liao $\mathrm{C}, \mathrm{He} \mathrm{H}$, et al. COVID-19 in Hemodialysis Patients: A Report of 5 Cases. Am J Kidney Dis 2020; 76(1):141-143.

16. Ferrey AJ, Choi G, Hanna RM, et al. A Case of Novel Coronavirus Disease 19 in a Chronic Hemodialysis Patient Presenting with Gastroenteritis and Developing Severe Pulmonary Disease. Am J Nephrol 2020; 51(5):337-342.
17. Akalin E, Azzi Y, Bartash R, et al. Covid19 and Kidney Transplantation. N Eng J Med 2020; 382(25):2475-2477.

18. Badawi A, Ryoo SG. Prevalence of comorbidities in the Middle East respiratory syndrome coronavirus (MERS-CoV): a systematic review and meta-analysis. Int $\mathrm{J}$ Infect Dis 2016; 49:129-133.

19. Channappanavar R, Fett C, Mack M, Ten Eyck PP, Meyerholz DK, Perlman S. SexBased Differences in Susceptibility to Severe Acute Respiratory Syndrome Coronavirus Infection. J Immunol. 2017;198(10):4046-4053.

20. Chen $N$, Zhou $M$, Dong $X$, et al. Epidemiological and clinical characteristics of 99 cases of 2019 novel coronavirus pneumonia in Wuhan, China: a descriptive study. Lancet 2020;395(10223):507-513.

21. Wang $\mathrm{D}, \mathrm{Hu} \mathrm{B}, \mathrm{Hu} \mathrm{C}$, et al. Clinical Characteristics of 138 Hospitalized Patients With 2019 Novel Coronavirus-Infected Pneumonia in Wuhan, China. JAMA 2020; 323(11):1061-1069.

22. Ahmed SB, Ramesh S. Sex hormones in women with kidney disease. Nephrol Dial Transplant 2016; 31(11):1787-1795.

23. Ajaimy $M$, Melamed ML. COVID-19 in Patients with Kidney Disease. Clin J Am Soc Nephrol 2020; 15(8):1087-9.

24. Lang J, Katz $\mathrm{R}$, Ix JH, et al. Association of serum albumin levels with kidney function decline and incident chronic kidney disease in elders. Nephrol Dial Transplant 2018; 33(6):986-992.

25. Henry BM, Aggarwal G, Wong J, et al. Lactate dehydrogenase levels predict coronavirus disease 2019 (COVID-19) severity and mortality: A pooled analysis. Am J Emerg Med 2020;38(9):1722-1726.

26. Haimovich AD, Ravindra NG, Stoytchev $S$, et al. Development and Validation of the Quick COVID-19 Severity Index: A Prognostic Tool for Early Clinical Decompensation. Ann Emerg Med 2020; 76(4):442-453. 